\title{
METODOLOGÍA FORMAL Y METODOLOGÍA DIALÉCTICA EN LA INVESTIGACIÓN ESTÉTICA
}

A la dilecta memoria de Paco de la Maza

1. Problema y método

El inexorable paralelismo

Un requisito fundamental que es necesario cumplir para llevar adelante la investigación filosófica, consiste en observar la similitud que existe entre los problemas planteados y el método que se sigue para resolverlos. A cada tipo de problema corresponde una especie particular del método, que va en paralelo al planteamiento de aquél, quedando implícito en el mismo a título de cómo resolver el problema, complemento sistemático de lo que sea el problema mismo, según los términos de su postulación específica. Nos proponemos en este ensayo mostrar y demostrar cómo este axioma universal de la investigación se verifica en la disciplina estética.

La investigación estética queda garantizada en la misma forma -y no podría serlo en ninguna otra- de la precitada similitud, puesto que su tarea se desenvuelve alrededor de dos polos, el problema y el método. La violación al paralelismo indicado repercute en una serie de extravios que deforman la estructura de nuestra disciplina y desvirtúan su unidad problemático-metódica en cuya sola virtud es posible mantener el inalienable principio metodológico de autonomía.

Estas desviaciones se observan a cada momento, no sólo en su adecuación fundamental, o sea la admisión de un determinado método para el problema genérico, sino también y sobre todo en las cuestiones específicas, que son manifestaciones parciales del mismo, afocado a cada uno de los aspectos particulares que implica en su desarrollo.

En torno a estos últimos surgen el mayor número de las confusiones que se presentan en la metodología estética; no obstante la admisión de un problema general y el correspondiente método, su desenvolvimiento origina las exploraciones particulares que se suscitan en gran volumen y llegan hasta la concreción de las obras, motivando en cada caso el empleo de una nueva dimensión metódica que puede mantener el parentesco necesario con la me- 
todicidad genérica, pero admite una variante específica según el grado de particularidad que asume en cada planteamiento.

En tales condiciones, es necesario subrayar el indispensable paralelo de la relación problemático-metodológica, no sólo en lo concerniente al enfoque general de la misma, sino también en sus desarrollos particulares, donde se presentan el mayor número de sorpresas y desajustes en la investigación. Así puede comprobarse en el contexto de la mayoría de los tratamientos estéticos.

En función de este paralelismo, la mejor forma de captar la disposición sistemática del método consiste en _establecer un símil con el cuadro de los problemas estéticos, en la inteligencia que a cada uno corresponde una modalidad metódica; se mantiene incólume la unidad que proviene de la postulación general y que tiene a la base el inviolable concepto de la unidad estructural del sistema. Alli se manifiesta y se recoge el concepto unívoco del arte: con él, la definición de sus problemas y del método adecuado para resolverlos.

\section{El camino por recorrer}

Concluimos que entre la problemática de cualquier disciplina y el método que sigue para resolverla, se establece el paralelismo por cuya virtud la definición del problema tiene implícito al método correspondiente, debiendo proseguir en esta similitud para llevar a buen término la pesquisa. Por definición, el método es el camino que ha de seguirse para ir de un punto a otro; la presentación de la problemática consiste precisamente en definir dichos puntos, señalando ipso facto cuál es la trayectoria por recorrer. La disyuntiva de emplear un buen o mal método depende de que el camino recorrido corresponda o no a la significación implícita en el problema.

He aquí por qué es necesario definir la problemática y en relación a ella establecer el sentido de la metodología estética. Desde luego, esta disciplina no escapa a la consideración general que acabamos de formular, sino que la verifica en todos sus términos. Se ha creído que es indiferente adoptar cualquier método, según la inclinación personal que pueda aflorar frente a tal o cual tema; hay quienes gustan apegarse a un método descriptivo, mientras que otros prefieren la lucubración abstracta; algunos se deciden por el enfoque historiográfico y otros más optan por ubicarse en el mundo de los valores. $\mathrm{Y}$ así sucesivamente.

El primer punto que nos interesa demostrar es que la selección del método no es cuestión subjetiva, y ni siquiera de elección entre varias posibilidades, porque, como hemos dicho, la definición del problema trae aparejada la caracterización del método para resolverlo. Sobre esta aporía veamos lo que sucede en nuestra disciplina. 


\section{El método y los métodos}

El primer punto que destacaremos es la existencia de diversos métodos parciales que operan en su respectivo campo, de análoga manera a como sucede con los problemas paralelos a dichos métodos. Esta funcionalidad de problema y método se observa en todas las disciplinas, no solamente filosóficas sino de cualquier índole; el pensamiento se erige a partir de un problema básico que es desenvuelto en sus diversas posibilidades, según los puntos de vista que se aplican a su tratamiento y diseñando la progresión arborecente en la cual funda toda disciplina científica la relación de particularidad a generalidad. La arborescencia contiene en su parte troncal al método, que corresponde al aspecto general del problema, y se polifurca sucesivamente a medida que avanza la inquisición particular en el campo de la experiencia, constituida en su extremo por los problemas casuísticos, que son en número infinito y se multiplican en el decurso de la evolución histórica. La imagen arborescente refleja con fidelidad el desarrollo de la metódica en relación a la problemática $\mathrm{y}$, una vez definida esta última, puede afirmarse la necesidad de reconocer al método primordial como fundamento de las derivaciones que se encuentran a cada paso de la ramificación.

Es de suma importancia no postular escuetamente tal o cual método y soslayar el problema a que se refiere; tampoco basta la simple afirmación de que puede haber muchos métodos para ser empleados en la estética, si no se agrega que cada uno corresponde a un problema específico, indicando que tanto los problemas como los métodos se organizan en un esquema arborescente. Tal es el sentido de nuestra tesis en relación a la dialéctica del problema y el método; la resumiremos en los siguientes puntos:

a) Relación. Existe una indisoluble relación entre el problema de cada disciplina y el método que ha de seguirse para resolverlo, correspondiendo ambos en paralelo a la misma naturaleza epistemológica.

b) Jurisdicción. No tienen todos los métodos, como tampoco los problemas, una misma jurisdicción epistémica; se ordenan en relación jerárquica, de generalidad a particularidad, de fundamento a fundamentado.

c) Intelección. La correcta polifurcación de los métodos situará a cada uno frente al problema que le pertenece, recorriendo la ramificación casuística que origina la experiencia, hasta la unidad troncal que radica en la teoría básica.

En estos puntos conclusivos se sintetiza la acción del método filosófico y genéricamente intelectivo; dentro de él se ubica la ciencia estética. Es natural que su solo enunciado no exponga el gran alcance heurístico que reportan las conclusiones al condicionar, ni más ni menos, la correcta marcha de los trabajos. Su postulación es indispensable para precisar la base para construir una secuencia metódico-dialéctica en relación a los problemas planteados. 
La secuencia metódica

Antes de avanzar a un nuevo estadio de la investigación, recapitulemos lo que se ha dicho. En virtud del paralelo que existe entre los problemas y el método, se establece la secuencia básica cuya prosecución indica implícitamente el desenvolvimiento dialéctico del método. El planteamiento de los problemas estéticos obedece a una concepción metodológica que funciona como base para la estipulación de su problemática. Ésta queda definida en virtud de una dialéctica secuencial que se pone en juego como supuesto de trabajo, existiendo de suyo como axioma de toda investigación. No podría ser de otro modo; el desenvolvimiento del pensar reclama la concepción de una idea regulativa sobre lo que debe hacerse, y en esta idea se apoya precisamente la metodología dialéctica del pensar.

La sola postulación de los problemas estéticos refleja un concepto del método que funciona activamente como norma directriz de la disciplina, agrupando los diversos aspectos que la constituyen; dos líneas paralelas representan a la metódica y la problemática. Por virtud de ese paralelo, la eficiencia metódica dependerá de su adecuación a la problemática y, recíprocamente, la resolución de los problemas se obtendrá a partir de una adecuada postulación del método. La secuela aporética en este capítulo consta de los siguientes momentos:

a) Definición. Es la definición del objeto estético y la toma de posición frente al arte.

b) Fundamentación. La estética como disciplina filosófica es la fundamentación del método.

c) Integración. Concepto integrativo del método; el doble sentido analítico y sintético del método.

d) Diversificación. Los momentos de diversificación en el método; de la experiencia a las leyes y viceversa.

e) Realización. Las obras de realización artística; los valores como supuestos metódicos.

f) Especificidad. Método general y método específico; hechos, hipótesis, verificación y reglas.

g) Historia. El método historiográfico; los estilos como fases de realización axiológica.

h) Legalidad. Autonomía y heteronomía del método; el arte, sus factores y las ciencias. arte.

i) Técnica. La técnica como método de trabajo; explicación técnica del 


\section{La proyección experiencial}

$\mathrm{E} 1$ aspecto más relevante de la heurística estética consiste en mantener una directa proyección en la experiencia, lo cual equivale a decir que la estética no puede construirse a espaldas del arte. El requisito de una teoría del arte a partir del arte mismo, parece demasiado obvio como para insistir en él; sin embargo, es mayor el volumen de teorías pretendidamente estéticas que han ignorado la necesidad concreta del arte, que el de las doctrinas que admiten la sujeción al hecho artístico.

Como es de suponer, el resultado de este alejamiento ha sido totalmente negativo; propicia lucubraciones y fantasías que a la postre se muestran contraproducentes. Son los artistas los primeros en rechazarlas; de ahí ha provenido cierto desprestigio de la estética entre quienes deberian ser sus primeros devotos, o sean los artistas mismos, y entre quienes los suceden en orden de proximidad a las obras, o sean los críticos de arte; tanto unos como otros opinan negativamente de la que llaman "estética filosófica", como si pudiera haber alguna que no lo fuese; emplean ese término con un sentido peyorativo que dista mucho de corresponder a la tarea edificante de la verdadera estética, que es siempre filosófica.

Se trata, sin embargo, de una opinión fundada, si nos remitimos a las múltiples aseveraciones que se cobijan espúreamente bajo el manto de la filosofía. Aunque parezca paradójico, el filósofo, en cuanto estético, debe ser el primero en rechazar la equívoca "filosofía del arte" -lucubrativa y fantaseosa- para que la verdadera filosofía del arte, o sea la estética, quede a resguardo en su propio terreno mediante el apoyo de la experiencia, manteniendo una tarea que en sí le es inalienable: La valoración objetiva de la obra de arte.

Uno de los factores que más han contribuido a esta confusión es el impulso natural del filósofo como el más avocado a la reflexión estética, de parecida manera a como lo sería también para una meditación lógica, ética y de cualquier orden filosófico. Esta creencia orilla al error, tantas veces cometido, de manejar temas del arte sin la suficiente compenetración de su esencia y sus procedimientos; en tal aspecto, el motivo que lo explica es diletantista, puramente subjetivo, y consiste en la inquietud que siente el individuo afecto a la filosofía, o quizá el filósofo de corte tradicional, por lanzar un cuarto a espadas en la lucubración estética, creyendo que desde allí se pueden abordar las demás. Ésta es una inducción teorizante, un auténtico vicio profesional, y no tiene mayor justificación que el sentido compulsivo o diletantista que señalamos. 
Atribuciones y fronteras

El único recurso para salvar el riesgo de la heteronomía metodológica consiste en proyectarse directamente sobre la experiencia, que equivale a la creación de obras de arte; hay que observarlas tal como son producidas, sin inventar nada que altere su naturaleza. Por ello - diciéndolo en términos comunes-, si de hablar de arte se trata, ningún método tan adecuado como observar lo que sucede en el arte mismo.

Efectivamente, una norma inconmutable de la estética consiente en reconocer que no se le pueden dictar al arte normas desde fuera; éste las produce según sus necesidades de creación, conforme a los propósitos del artista y los recursos de que dispone; cualquier teoria estética sobre el arte debe partir del arte mismo, arraigar en sus obras, confrontar su naturaleza y ceñirse a lo que revela en su estructura material y en sus formas de realización.

Aquí encontramos las atribuciones y fronteras metodológicas de la estética; las primeras, en razón directa del valor realizado por el arte y excogitado por la estética; las segundas, porque señalan la imposibilidad de trascender esta demarcación experiencial. Cuando falta el apoyo del arte para la verificación de las teorías estéticas, se convierten ellas en una vana lucubración, donde es posible decir todo puesto que nada se puede comprobar.

En esa perspectiva es necesario destacar cuáles son sus posibilidades y dentro de qué limitaciones deberá desenvolverse; con todo y su tendencia de universalidad, la estética se sujeta a radicales especificaciones metodológicas de autonomía, lo cual significa desarrollarse con estrictas limitaciones en sus fronteras; debe respetar las atribuciones ajenas a cambio de exigir que se respeten las suyas. Este requisito es tanto más definido para la estética por cuanto un gran número de heteronomías amenazan continuamente en razón de las disciplinas colindantes, al tratar cuestiones del arte cuya liminaridad es forzosa y de la cual debe procurarse la conjunción, con el mismo énfasis que evitar la confusión.

Finalizamos nuestro primer enfoque sobre el método estético reafirmando la necesidad de vincularse a la experiencia para efectuar la explicación del problema, que es el arte expresado en obras; este requisito es obvio, pero hay que insistir en él para desterrar definitivamente la especulación tan socorrida en este campo y abrir el camino por donde se desenvuelva la investigación, cuyas características apuntamos en calidad de categorías dialécticometódicas. A ellas hay que volver inmediatamente la atención. 
2. LAS Gategorías metónicas

\section{La definición como método}

El primer paso en el método de la estética es el mismo que corresponde a cualquiera otra disciplina: la definición autónoma de su objeto. No podría concebirse un procedimiento cognoscitivo que no tuviera como base la satisfacción del requisito definitorio; en él se expone la esencia del problema. Cualquier reflexión que deba referírsele tendrá como punto de apoyo una definición básica que contenga sus notas esenciales. La definición dialéctica del objeto tiene como resultado impulsar la dinámica del conocimiento; médiante la definición dialéctica, una palabra se transforma en concepto y el enunciado de un objeto es la unidad de significación del problema.

El sentido dialéctico de la definición se infiere por el enlace sucesivo de varios procesos conceptuales que se vinculan con referencia a un mismo objeto, por más que su eslabonamiento tiene lugar en diversos planos de la actividad epistémica. En el caso del arte es particularmente difícil efectuar la concatenación conceptual, considerando la raíz intuitiva de los elementos estéticos y la inminente proximidad que guardan con respecto al ámbito emotivo, quizá irracional.

Esta dificultad se pone de relieve a partir de la definición primaria del arte; no es una coincidencia que numerosas posturas hayan concluido en la imposibilidad de definir al arte, en tanto que otras se pronuncian con la misma intención mediante un simple soslayo del problema. Tal es el caso de las opiniones que dan por sentado el concepto del arte, o se remiten a un dato intuitivo y a una vivencia subjetiva que aceptan el requisito primario de referencia. La idea primaria consiste en este caso en el empleo de sentidos consagrados por el uso común, en referencias vivenciales y dogmáticas sin la integración epistémica que requieren todos los conceptos.

Naturalmente, el "método subjetivo" se refugia en la intuición y soslaya el problema definitorio, quedando esparcidos al azar los conceptos cotidianamente empleados que, por carecer de la suficiente explicitación dialéctica, se ponen a espaldas del procedimiento racional inherente a toda disciplina. De esta reflexión en torno al método dialéctico concluimos que sus reflexiones se complementan a base de un encadenamiento de conceptos y juicios que prosiguen la secuencia determinativa de la estética.

\section{La metódica filosófica}

Suele soslayarse, cuando se trata del método especial, que se aplica a una rama de la filosofía, y por consiguiente, participa de su problemática general, axiológica y metodológica; debe conjuntar sus intereses en una misma dispo- 
sición excogitativa frente al hecho de la cultura. La ubicación del método estético en cuanto derivación del método filosófico, explica la raíz que mantienen las doctrinas particulares con respecto a la experiencia cultural y al mismo tiempo define su alcance en los términos de autonomía que son indispensables.

.Ésta es una de las grandes verdades que, por obvias, suelen pasarse por alto, principalmente cuando se investiga en una disciplina particular sin haber llegado al fondo de la metodología general. Es muy frecuente que los estudios de estética se efectúen en un plano diletantista y se transite empíricamente de un problema a otro, de una fase a otra, en las varias dimensiones que presenta el hecho artístico, precisamente considerado como hecho concreto y vital. En este enfoque permanece sin depurar la unidad metodológica y la correspondencia aporética de cada planteamiento; también las implicaciones formales o dialécticas que supone la adquisición de autoconciencia metodológica. Así se publican una gran cantidad de trabajos, respetables por sus observaciones sobre el arte, pero confusos en cuanto a la delimitación aporética de su planteamiento; confunden a la estética con la psicología del arte, la historia, la sociología, etc., y aunque las investigaciones sean valiosas en sí mismas, por su contenido, desmerecen por falta de rigor y por las confusiones que, a pesar de todo, se presentan inexorablemente en el contexto.

Si el requisito de metodicidad se tomara en cuenta con la amplitud que merece, la "filosofía del arte" debería aceptar, por principio, la obligación de justificarse como parte de un vasto sistema nomotético y salvar el confuso panorama donde contemplamos, por ejemplo, una ontologia entendida conforme a un método, una ética a la cual se aplica un método diferente, una estética que parte de premisas metodológicas distintas; y así sucesivamente. El hecho de inscribir el método de la estética en el sistema de la filosofía garantiza su validez en la medida que exhibe cierta congruencia con los trabajos colaterales, apoyándose en el principio de integración metódica que confiere carta de ciudadanía dialéctica a todas las polaridades del filosofar.

Este requisito se cumple únicamente en los sistemas de gran madurez, que acusan una sensible analogía en sus planteamientos y en sus métodos, pero son muy contados los trabajos eventuales que pueden evidenciarlo con pulcritud. Hablando en rigor, únicamente se han dado apuntes a la integración sistemática de la filosofía -cuando menos en nuestro medio- sin que se le haya cumplido a satisfacción; prueba de ello es que en México, y quizá en todos los países de habla hispánica, no se ha producido un solo sistema de filosofía. Quedan siempre amplios resquicios por donde se cuela un sinnúmero de anomalias y desajustes que violan el principio de la homología metódica.

En la moderna filosofía estructural de los valores se contiene la mayor explicación del método dialéctico en paralelo a la más profunda conciencia 
sistemática, porque la estructura de los valores polariza el supremo denominador para desenvolver un sistema filosófico en su óptima inclusión a la organicidad de la cultura. En un nivel inferior a la sistematicidad axiológica se hallan la mayor parte de los intentos por obtener el fundamento dialéctico del método mediante su ubicación en la unidad orgánica del sistema. A ello se debe también que la mayor parte de dichos ensayos sean frustráneos en su vertebración metodológica y, desde luego, en su fundamentación axiomática.

$\Leftrightarrow$

\section{Análisis y sintesis}

Aunque la estética es una rama de la filosofía y su método debe ser necesariamente filosófico, un buen número de investigaciones se promueven con independencia de la ortodoxia doctrinaria, más allá de las posturas oficialmente reconocidas, como una especie de examen analítico que se produce por el interés de captar el sentido vital del arte. Esto es lo que sucede en el campo de la "crítica" espontánea que en cierto modo es una estética desenvuelta frente a la realidad arlística mediante el ejercicio natural dé la razón. El método empleado en este caso es empírico y consiste en una descomposición de los elementos que constituyen la obra para examinarlos uno junto al otro y deducir la acción que cada cual desempeña en la composición misma. Esta fase de análisis es indispensable para la ulterior configuración de una problemática sintética.

El método complementario del análisis consiste en una sintesis que reconstruye la unidad dialéctica de la obra a partir de las conclusiones generales que se obtienen mediante el examen formal de los elementos. Esta segunda fase de recomposición tiende a emitir el juicio de valor y desemboca en la ubicación concreta, que corresponde a la singularidad ingénita de la obra, se produce con mayor frecuencia en el seno de la crítica del arte, que constituye el extremo casuístico de la estética, tanto general como especial, referida a los conceptos particulares de valor, en la realización también particular que adquiere según los géneros y especies en que se verifica. No necesitamos insistir en la complementariedad que adquieren las fases analítica y sintética, pues queda en evidencia con sólo reconocer, aunque fuese en el aspecto más superficial, la acción dialéctica inherente a ambas fases metodológicas.

\section{La ley y la experiencia}

En un sentido similar se desenvuelve la implementación de las leyes obtenidas a título de conclusiones sobre la experiencia; en el caso de la estética, ese tipo de conclusiones corresponde a las que se han designado como 
reglas, o sean las normas técnicas que privan en la ejecución de las obras y que el artista maneje de acuerdo a su estilo; el estético las descubre mediante el ejercicio del método autónomo-dialéctico. La importancia de dichas reglas consiste no solamente en exponer la pauta de realización artística, sino en ejercer el criterio de valor, por lo que, en cierto modo, constituyen un andamio y a la vez un dictamen axiológico de la belleza.

Dicho dictamen no puede ser arbitrario, ni definitivo; encontrará la razón de validez en el campo artístico del cual ha partido y en el cual se concreta, si la observación efectuada corresponde en fidelidad a la obra. L $\ddot{x}$ invalidez de toda pretensión perenne o dogmática consiste en la perentoriedad de cualquier sistema estático, ya se cobije con el manto de un estilo, de una escuela o en un solo momento de inspiración. En cualquier caso, existirá una trayectoria ulterior que evoluciona históricamente en las formas dadas, tendiendo a realizar el consabido axioma estético de la innovación formal de los estilos. En esas condiciones, y considerando que la filosofia no dicta al arte sus reglas, el método de la estética consistirá en un permanente oscilar entre la facticidad de las obras y la normatividad de las reglas, teniendo en cuenta la movilidad de éstas con respecto a aquéllas. Sólo así puede concebirse la metodología para comprender dialécticamente las reglas del arte, mismas que existirán en el plano general de las normas siempre y cuando se verifiquen a nivel concreto de los hechos.

\section{El valor y el método}

La realización de lo bello constituye la finalidad primigenia del arte; no puede sustituirse por ninguna otra de las que aparentemente justificarían a la actividad estética en función de ciertas finalidades extraestéticas. La belleza es, por así decir, el objeto que tiene frente a sí el artista y cuya explicación constituye la tarea medular estética. Así ¿̨cuál puede ser la determinabilidad que ejerza el objeto sobre el método de esta disciplina?

La respuesta es que la determinabilidad consiste nada menos que en la acción desempeñada por el valor en su calidad de criterio normativo para la inquisición metódica, pues cada concepto de lo bello actúa en calidad de una norma general para enjuiciar el valor de las obras. La faena estética no puede acometerse sin la norma que define el criterio de valor; mientras más abundante sea la documentación sobre las modalidades axiológicas y las formas técnicas del arte, habrá mayor posibilidad de establecer el correspondiente criterio valorativo. No se concibe, por ejemplo, que un crítico de arte pudiera pronunciar su opinión partiendo exclusivamente de la contemplación pasiva, sin tener como supuestos metodológicos los principios que exponen el sentido dinámico de la belleza, según las variantes de época, estilo y sensibilidad individual, que matizan a la obra artística. 
Dichos supuestos se contienen simultáneamente en la estética, en la teoría del arte y en la técnica de realización; en la primera, porque alberga el criterio de belleza, definido según las coordenadas polares de referencia; en la segunda, porque establece el poder expresivo de los elementos que se conjugan para rèalizar la obra; y en la tercera, porque indica los procedimientos concretos que se adaptan a la mejor forma de realizar la expresión. El criterio de valor está determinado simultáneamente por esos tres parámetros epistémicos; la pauta metodologica correspondiente a cada categoría consiste en un criterio axiológico que sirva como punto de partida a la investigación, ubicándolo simultáneamente en el ámbito de la estética propiamente dicha y canalizado a la teoría, la técnica y la historia del arte. Éstos son los tres planos dialécticos donde se promueve la realización, la justificación y el valor de la obra.

\section{La especificidad metódica}

La obtención de reglas en el arte obedece a la necesidad de concebir una normatividad teorética por encima de la facticidad empírica, teniendo por objeto regularla mediante una adscripción nómica que señale la especificidad inherente a toda forma de pensamiento. Esta necesidad regulativa ha sido frecuentemente impugnada por los artistas, que quisieran desenvolverse con independencia de cualquier obligación para acatar reglas de toda especie; pero no es posible evitar el empleo de reglas si se quiere lograr la concepción estilística; ella tiene siempre como base una correspondencia de las obras y las reglas, con la concomitante verificación de éstas en aquéllas.

La adecuación de las obras a las reglas que rigen en cada estilo, implica la correspondiente categoría metodológica en la cual se exhibe el tránsito paulatino de la singularidad a la universalidad que asumen las reglas en su propio estilo, por cuya sola virtud se pueden interpretar, relativamente, como leyes estéticas. Así pues, la especificidad metódica consiste fundamentalmente en el reconocimiento del estilo de las obras que se presentan como objeto de estudio ante la consideración estética, la formulación de hipótesis que incluye la obra en un determinado estilo, y la codificación de reglas técnicas que equivale a la concepción nómica de la época, llegando por último a su verificación en el ejercicio del método dialéctico, que se efectúa principalmente en la crítica y la historiografía del arte.

Obsérvese que esta disposición dialéctica corresponde en el campo estético a la secuencia que se manifiesta en todas las modalidades del pensar, y por excelencia en el pensamiento científico; el tránsito de los hechos a las leyes por medio de las hipótesis, y su verificación en los hechos mismos, es el esquema metódico que promueve sin excepción a todas las formas del pensamiento científico. 


\section{Automomia y heteronomia}

Por lo que hemos dicho, el aspecto fundamental del método se determina a partir de la ubicación directa del problema estético en el arte, lo cual se efectúa una vez consumado el deslinde entre los problemas estéticos y extraestéticos, definiendo para cada uno el alcance jurisdiccional de sus axiomas y aplicándolos en calidad de ley explicativa para cada área problemática del arte. El mantenimiento de los principios dentro del territorio que les pertenece, es la condición metódica de autonomia, y equivale a la aplicación de la ley propia a cada problema.

No necesitamos insistir en que la verdadera explicación ha de efectuarse con el descubrimiento de la ley propia y que dicha ley debe ser verificada en su objeto para consagrarse como un principio epistémico de facultad explicativa; cualquier repetición para subrayar este requisito parecería reiterativa si no fuese por la frecuencia con que se le viola en la práctica, incurriendo en el error heterónomo que es la confusión de unos problemas con otros; este error repercute en la deficiente interpretación de la temática estética y en la configuración de las tesis heterónomas respectivas.

El requisito metódico de autonomía exige que la investigación estética encuentre para la esencia del arte una fundamentación inherente al arte mismo, y sólo a él, a la vez que sitúa periféricamente los principios que explican cada una de las cuestiones extraestéticas. La autonomía se resguarda con el problema de la belleza, exigiendo que la estética, y sólo ella, sea reconocida apta para desenvolver el tema de lo bello como esencia del arte.

La heteronomía estética es el polo opuesto a la autonomía; se le puede considerar como el antimétodo, el error metódico por definición; consiste en confundir el perímetro de los problemas y las leyes explicativas; esta confusión origina el gran volumen de equívocos que contiene la disciplina del arte. No se trata, pues, de una concepción absurda de las cuestiones estéticas, pụes si así fuera el error heterónomo no representaría ningún peligro, a primera vista sería descubierto en su flagrante contradicción. Pero dado que la heteronomía proviene de hacer ilegítimamente extensivo un tipo de conocimientos que valen en su propio campo, suele disfrazarse bajo el engañoso ropaje de una verdad a medias. La justificación de esta última no puede hacerse más allá de sus propios linderos, no puede rebasar las cotas de su parcela.

La heteronomía no sólo se presenta en la invasión de una disciplina por otra, como sucede, por ejemplo, con la explicación psicologista o matematicista del arte; en una misma ciencia pueden registrarse errores heterónomos, lo cual se observa con gran frecuencia en la estética cuando se quiere presentar alguna de las artes como preponderante sobre las demás. Este error es inducido principalmente en las cuestiones de estética comparada, cuando 
pretenden la hegemonía para alguna de las artes. Si queremos evitar este error, será necesario resguardar a la autonomía como guión metódico inviolable, no sólo para defender la independencia de cada disciplina, sino también para garantizar la correlación dialéctica de sus problemas y sus principios, manteniendo congruente la estructura interna de la estética en correspondencia con la naturaleza de los valores realizados en el arte.

\section{La historiografia como método}

No sería posible efectuar una caracterización del método estético sin referirse al procedimiento que denota el enfoque distintivo de observar a la realidad artística en el curso de su evolución histórica. En efecto, la historicidad del arte concierne directamente a su contenido axiológico; no es posible remplazar a la apreciación evolutiva de la vida artística por ninguna otra, ya que la historicidad es una de sus categorías insustituibles.

La proyección del método histórico se observa principalmente en el tratadismo que pretende ser de estética y resulta a la postre de historia del arte, observada muchas veces en su dimensionalidad psicológica y sociológica. Naturalmente, ésta es una posición heterónoma; pero la historiografía autónoma se contiene en el reconocimiento de la evolutividad de los valo. res, los cuales dependen de las unidades de realización en que se producen.

El efecto metodológico en la historia de la estética se traduce en la impostergable necesidad de enjuiciar la creación artística a través de su evolución diacrónica; así se comprueba la relatividad de los valores de acuerdo a las unidades que hemos señalado: época, estilo, escuela. Lo contrario de esta metodización consistiría en la creencia en que las formas imperantes en una época deberían valer para siempre y en todo lugar, cayendo así en el más rotundo dogmatismo. Por ello, la historicidad va aparejada a la relativización que se contiene en el reconocimiento de la vigencia temporaria de los estilos artísticos, en vez de quererse extender universalmente y sin limitación alguna.

El reconocimiento de la historiografía como método para la investigación estética no debe significar una apertura a la heteronomía respectiva, o sea la confusión de la estética con la historia del arte y la canalización del fundamento axiológico de la obra hacia la parafernalia confusionista de la anecdótica casuística. Esta última se aviene como complemento de la historia propiamente dicha, que es fundamentalmente sincrética; señala el retorno a la concreción diacrónica después de haber recorrido las fases de la polidimensionalidad analítica en las diversas funciones colaterales de la creación artística.

La historiografía como método significa el reconocimiento de que las formas estéticas evolucionan de acuerdo a los determinantes diacrónicos, entre los cuales figura ese abigarrado mundo de los acontecimientos que 
tanto complace a los historiadores, incluyendo la espléndida fusión de historia, psicología y sociología, que se produce en la biografía de los artistas; de ahí su importancia como factor auxiliar de la estética. Obviamente, la biografía se encuentra en el justo medio de las tres ciencias mencionadas, para las cuales no es sólo un factor colateral, sino un elemento constitutivo.

Ahora bien, cabe preguntar hacia dónde se dirige la proyección historiográfica de la estética, si no al abigarrado mundo del quehacer cotidiano en que generalmente se traduce. La solución se encuentra en el plano de la técnica; lo que a la verdadera historia estética interesa es la evolución de las formas, pero no en cuanto resultante del casuismo psico-socio-históricobiográfico, sino como la gran respuesta que ofrece el artista al problema de la creación, es decir, como fórmula sucesiva y a la vez integrativa que tiene a un lado las necesidades de expresión a través de la época y del estilo, y al otro, las expresiones realizadas en obra mediante el acoplamiento de los materiales a las técnicas de trabajo.

\section{La técnica como método}

Por ello desembocamos necesariamente en la última de las categorías que hemos fundado para el reconocimiento del método estético: la técnica. Sabemos que consiste en los procedimientos empleados para llevar a cabo la expresión artística. Dichos procedimientos desempeñan por sí solos una función creativa y actúan también en calidad de pauta metodológica para la estética, desde el momento que su investigación exige el reconocimiento de la propia técnica para captar los valores respectivos. Además, el correcto ejercicio de las reglas produce valores autónomos que son llamados precisamente valores técnicos o calidades formales. La concepción integral de lo bello tiene como base la fórmula constitutiva de la técnica, o sea la adecuación del material a la forma, para expresar el contenido. Esta funcionalidad está implicada en la técnica de las mejores obras, que se deben precisamente al empleo de las mejores técnicas.

Cuando la estética pretende desligarse del requerimiento tecnológico, suele caer en digresiones casi siempre desvirtuantes, que aparecen como resultado de la ardiente imaginación de los filósofos abstractos; este tipo de estética atécnica se encuentra a cada paso de la llamada "filosofía del arte" y consiste en postulaciones subjetivas que poco o nada tienen que ver con la esencia constitutiva del arte. A cambio de ello, cuando se aplica rigurosamente el conocimiento formal de la técnica a la interpretación axiológica de la obra, se produce la verdadera estética que enjuicia y explica los valores del arte a través de su realización en el acto creador, develando los procedimientos técnicos que se han empleado; este método formal es indispensable para entender cabalmente el sentido de la obra artística. 


\section{Complejidad del método}

La necesaria inclusión de las categorias que señalamos indica de modo elocuente la gran complejidad que adquiere el método en la estética cuando se le ejercita dialécticamente, esto es, cuando se dirige a la comprensión del arte en todas y cada una de sus facetas autónomas, para no hablar de las heterónomas. La exposición de las categorías metódicas constituye el procedimiento analítico y formal para establecer la estructura básica del método, cuyo ejercicio las reúne en forma sintética mediante su aplicación unitaria a la valoración de las obras. El especialista reconocerá la necesidad de dichas categorías así como la deficiencia doctrinaria que se produce al omitir cualquiera de ellas. Nosotros destacaremos en forma conclusiva las consecuencias sincréticas de las categorías que postulamos.

La posición definitiva para avanzar en el estudio de la complejidad metódica, es precisamente el reconocimiento de dicha complejidad como resultante de los problemas que surgen en las diversas facetas del arte.

\& Hay que tener en cuenta, en primer término, la proyección concreta sobre la experiencia, por medio de la cual se establece contacto con el objeto $\mathrm{y}$, por consiguiente, la posibilidad real de la predicación.

También es necesario delimitar las fronteras que circunscriben a la estética, no sólo para definir cuál es su campo, sino también para reconocer los que colindan con ella.

La definición es el primer paso para objetivar todo conocimiento; de ahí el imperioso requisito de definir el arte y los conceptos-problemas que concurren a determinarlo.

La incorporación de la estética en un sistema filosófico se obtiene a través de la coparticipación de los principios axiológicos que actúan en calidad de axiomas para todas las disciplinas que lo integran.

La dialéctica del método es otra categoría que implica la simultánea y complementaria acción de las fases analitica y sintética, o sea la descomposición y recomposición de los elementos que participan en la obra.

El objetivo del método es alcanzar conocimientos suficientemente explicativos para que puedan tomarse como normas técnicas de construcción en el arte, y se traduce en la producción de las reglas artísticas y su verificación en la experiencia.

El valor desempeña una función de primer orden como criterio metodológico, puesto que la estética tiene por objeto valorar las obras de arte; por ello, el criterio que permite definir cualquier sistema autónomo es el valor.

La dialéctica de autonomia y heteronomía es la más radical o básica de las categorías que condicionan la metodicidad; es necesario tenerla en cuenta y preservarla a cada uno de los pasos de la investigación.

La historiografia descubre el sentido evolutivo del arte y condiciona la 
ductilidad de los conceptos metódicos de acuerdo a la evolución de las formas a través del tiempo.

La técnica muestra cómo se lleva a cabo la adaptación de la forma al material, según el contenido que se quiera expresar; constituye una categoría metódica desde el momento en que para descubrir el valor del arte hay que seguir la pauta tecnológica.

He aquí, pues, en breves palabras, el significado de las categorías metódicas del arte, o sean las condiciones que integran y posibilitan la acción del método en la estética. Dichas categorías nos han servido como hitos para el examen que practicamos sobre el problema metodológico: dialéctico y formal.

\section{LA ESTÉTICA DIALÉCTICA}

\section{Unidad y dinámica}

La unidad de las categorias expone el ejercicio dialéctico del método y se reproduce en la interioridad del proceso artístico; por consiguiente, es línea paralela al método estético. No podría ser de otro modo; el.proceso de la creación artística queda investido de una indeclinable unidad; la fragmentación de sus categorias no tiene más sentido que el de un análisis perentorio, efectuado para entender mejor la disposición de las funciones metódicas. Esta perentoriedad debe resolverse en la reintegración de las categorias en la unidad sintética del método restaurando así la fragmentación analítica efectuada artificialmente a guisa de cortes anatómicos para distinguir con claridad sus elementos constitutivos.

En esta unidad dialéctica se produce la complementación e interpenetración dinámica de sus elementos; complementación, porque al actuar como parte de un proceso adquieren sentido en la totalidad del mismo, e interpenetración, porque la acción mancomunada que desempeñan impide que sean ajenos entre sí; al contrario, se vinculan tan estrechamente que cualquier deficiencia o plenitud en alguno repercute con el mismo signo en los demás.

Esta complementación dinámica erige la organicidad estética en correspondencia a la organicidad genérica de la filosofía, cuyos elementos y categorias constituyen funciones direccionales que se complementan mutuamente. La fundamentación orgánica de la estética es la mejor garantía para discernir la integración de los trabajos, a partir de sus diferentes categorías; junto con la indefectible unidad se establece la dialéctica estética, erigida en forma autónoma con el proceso creador del arte, que es fundamentalmente dialéctico. En las siguientes páginas trataremos de elucidar las funciones principales de la estética dialéctica; ella es en rigor la única estética posible, la investiga- 
ción orgánica que encuentra su respaldo más elocuente en la unicidad y organicidad sistemática de la filosofía.

\section{La estética a priori}

El tratadismo clásico del método dialéctico suele orillar a dos posiciones que es necesario deslindar en la clarificación metódica de esta disciplina. Dichas posiciones corresponden a la distinción tradicional de los juicios $a$ priori y a posteriori; suele cifrarse la propiedad de los primeros en ser construidos independientemente de la experiencia, y de los segundos, a partir de ella. Como en este caso la experiencia es el arte, una estética a priori sería la que formulara sus reglas con independencia de la creación artística, y aun antes que se produjera; la estética a posteriori trataría la elucidación de sus principios después de una consulta con la experiencia. Ante esta disyuntiva cabe preguntar: ¿son ambas posturas solventes para la tarea encomendada a la estética? $\mathrm{Y}$ en caso contrario, ¿cuál de ellas tiene validez y cómo debe refutar a la otra?

La estética a priori tiene pocas probabilidades de subsistir si la consideramos con libertad suficiente para implementar un conjunto de reglas que soslayen el ejercicio vivo de la experiencia y, por consiguiente, el deseo y la necesidad de expresión por parte de los artistas. Hablando en rigor, son ellos quienes determinan el sentido de su creación; lo hacen en ejercicio de la libertad artística, sin más límite que su talento y sus facultades que conjugan en el empleo de una técnica. ¿Cómo podía entonces edificarse, con visos de verosimilitud, una doctrina que pasara por alto la jurisdicción soberana del artista y su obra?

Ciertamente, los juicios a priori tienen validez apodíctica, pero en el campo científico, en el dominio de las ciencias puras, especialmente en las matemáticas. Recapacitando sobre al experiencia estética, observamos que se encuentra totalmente arraigada en el mutable terreno de la facticidad y que sus preceptos pueden ser violados en cualquier momento, sin menoscabo de la virtud expresiva que constituye el desideratum del arte. A tal grado opera esta libertad que dichos preceptos ni siquiera alcanzan el rango de leyes, aunque fuesen de validez asertórica como algunos enunciados de la ciencia natural; son meramente reglas de construcción que tienen alcance preceptivo, no legislativo, quedándoles ajeno el valor apriorístico que se localiza en las ciencias puras.

Podemos concluir en forma terminante la imposibilidad de una estética radicalmente a priori, y condenar de paso todos los intentos que con ese propósito se han efectuado en la historia de la filosofía. Son bien numerosos, por cierto; y ocupan quizá la mayor parte de las doctrinas estéticas que pertenecen a la familia idealista, mas a pesar de ello contienen fórmulas 
abstractas y proceden con una imaginación invälida respecto a la experiencia. Son a la postre ineficaces para promover la deseada fundamentación del hecho artístico.

\section{La estética a posteriori}

A diferencia de la estética a priori, que no se justifica frente a la irreductible mutabilidad del arte, la estética a posteriori tiene las mayores probabilidades de subsistir como disciplina realista y progresiva, estableciendo sus problemas sobre una base firme y desenvolviéndolos hacia el horizonte cada vez más amplio de la creación artística. Razón de ello es que, admitiendo la necesidad de dirigirse a la experiencia, atiende a la verdadera naturaleza del arte y se circunscribe a ella, sin elaborar teorías abstractas ni menos aún imponerlas arbitrariamente al mundo soberano de la creación artística.

El sentido de la estétiça a posteriori consiste — según hemos dicho- en sujetarse a la experiencia artística y explicar el valor contenido en las obras, mediante su reducción técnico-formal y su ubicación en una época o estilo determinado. Obsérvese que la función explicativa no se efectúa en términos de una ideología, sino aplicando los conceptos que derivan de la experiencia y encuentran en ella el mejor fermento para su realización.

La estética a posteriori es la estética concreta, la que toma en cuenta la realidad de las obras que examina para emitir el juicio valorativo que procede en cada caso. Hablando en rigor, la única estética posible es a posteriori, pues el arte es una actividad mutable, fáctica y prescriptiva, a diferencia de las ciencias puras donde encajan los principios a priori como fundamentos de razón. Así como no tiene sentido hablar de una matemática a posteriori, que tomase los conceptos de la realidad, tampoco cabe hablar de una estética a priori, que inventara las normas creadoras con independencia del arte, pretendiendo imponerlas a voluntad en un dominio imprevisto por sus lucubraciones.

El contraste entre el arte y las matemáticas explica cuál es el origen de la estética apriorística, que resulta inverosímil con respecto del arte mismo; proviene de generalizaciones científico-matemáticas como de abstracciones filosófico-lucubrativas, de suerte que ningún caso abona el fundamento necesario para edificar una tarea que, repetimos, tiene como punto de partida la realidad de las obras y no puede apartarse de ellas, habida cuenta de la libertad que mantienen los artistas para cambiar a voluntad el sistema de reglas que han empleado hasta un cierto momento, más allá del cual las normas y reglas de estilo dejan de tener efecto. 


\section{La universalidad estética}

Ahora bien, por más dominante que sea el método a posteriori en la investigación estética, jamás podría llegar a un aposteriorismo absoluto, cual sería el que se agotara íntegramente en la empirie renunciando por completo a toda norma, ya no digamos de universalidad, cual corresponde a las ciencias puras, pero sí de generalidad, como puede aplicarse en este caso. La crítica que hemos efectuado de la estética apriorística se dirige contra la pretensión de obtener leyes universales para el arte, y más aún, de obtenerlas a espaldas de la experiencia; pero esto no significa que deba renunciar a toda generalidad, siempre y cuando la haya obtenido mediante una inducción limitada, a partir de las obras de arte y circunscrita a sus propias categorías.

En estas condiciones, la estética alcanza una cierta generalidad consagrada en las reglas técnicas, que son precisamente reglas y no "leyes", porque están sujetas a la mutabilidad que imponen las diferencias de construcción y de temperamento en el arte. El grado de generalidad es relativo, como al fin de cuentas es relativa cualquier generalidad; en este caso, la generalización está circunscrita a categorías de orden histórico y se impone a través de los estilos que privan en cada época, de las escuelas que integran cada estilo y de los artistas que pertenecen a cada escuela. Hay ocasiones en que no solamente un artista, sino también una obra, alcanzan una sui generis univer. salidad estética que connota un prototipo de época, de estilo y de autor; es el caso de las obras más representativas, de las que mejor realizan un tipo de expresión, de las obras "perfectas" y "acabadas" que se reconocen con la categoría de obras maestras.

En tal caso, la universalidad en la determinación estética corresponde en el mismo nivel a la universalidad en la realización artística y, paradójicamente, conllevan la mayor individualidad posible del arte. Si decimos universalidad es teniendo en cuenta las limitaciones que este concepto presupone, fundándonos en el tipo de universalidad que se localiza en una obra maestra como unidad suprema de significación expresiva y de realización prototípica. Objetivación insuperada - por ello mismo, permanente y universal- del sistema estético a que pertenece y comparable sólo a otra del mismo rango: la obra maestra es igual a la obra maestra. Decimos, por ejemplo, que la Venus de Milo es universal porque realiza los cánones clásicos de la belleza física y configura un determinado "universo"; el establecimiento de dichos cánones produce también una estética "universal", en el mismo sentido y con las mismas limitaciones que se reconocen en la obra.

Así pues, la universalidad estética difiere claramente de la universalidad cientifica; constituye un mundo expresivo que realiza en plenitud sus postulados mediante el empleo de una técnica formal específica, sujeta a determinadas reglas estilísticas que esta disciplina pone de relieve, alcanzando 
de este modo la determinación universal en su propio dominio de acuerdo a sus propias categorías.

\section{El método dialéctico}

La necesaria participación de conceptos universales en una disciplina esencialmente experiencial $\backslash$ y aposterioristica, como es la estética, orilla a un diálogo entre las dos fases de la investigación, la que se proyecta en la realidad para tomar de ella sus datos, y la que se dirige a los principios generales para establecer su función explicativa. Este diálogo consiste, por el lado universal, en el concepto mismo del arte, y por el concreto, en las obras que acoge la experiencia. Entre el polo universal que define al arte como expresión intuitiva del sentimiento, y el polo singular que cristaliza las formas individuales de cada obra, hay una serie de planos que realizan el acercamiento gradual de ambas posiciones, tomadas como puntos de referencia para la investigación. No se trata de una mera dualidad entre lo universal y lo singular, como si fueran extremos irreductibles, sino de un continuo tránsito que implica la ascensión de las obras a los principios y el retorno de éstos a las obras.

Podemos considerar el método dialéctico en cuanto unidad dinámica de una pluralidad, correspondiendo a la dinámica del objeto que le ocupa y ha de ser explicado también dialécticamente. Por regla general se caracteriza dicho método como el encuentro de una tesis con su antítesis para fundirse en la síntesis; pero este sentido antagónico está superado por un concepto más dinámico y más dúctil, consistente en la complementación de los elementos distintos en el seno de una unidad orgánicamente establecida. En el caso del arte, el concepto antagónico de la dialéctica diría, por ejemplo, que la naturaleza representa la tesis para el artista, que su temperamento constituye la antítesis, mientras la obra de arte derivaría como una síntesis del parámetro objetivo y el subjetivo, que representan a la realidad y al artista, respectivamente.

Pero con este diseño se recae en el genetismo heterónomo que desvía el centro de gravedad de la investigación. En términos de autonomía, el concepto complementario del método dialéctico se refiere exclusivamente a la obra de arte y queda inmerso en la experiencia estética, sin necesidad de recurrir al proceso genético, psicológico-temporal, o histórico-biográfico, ni tampoco a la clásica acepción del choque tesis-antítesis que, según hemos dicho, está superado por la función complementaria de los elementos que integran una obra. En este sentido, la dialéctica estética encuentra algunas principales realizaciones que verifican la complementariedad del orden histórico-estilístico, axiológico-calológico y estructural-técnico, según veremos a continuación. 


\section{La dialéctica histórica-estilistica}

Observando históricamente al proceso artístico, localizamos la complementación dialéctica mediante el lugar que ocupa una obra en cierto periodo, correspondiendo a determinado estilo que refleja el carácter general de la época. Los rasgos individuales encuadran en ese estilo, que constituye un elemento integrante de la época y refleja asimismo el espíritu y la cultura de su tiempo. La realidad estilística es explicable en función de la unidad orgánica y expresiva que asumen ciertos caracteres generales cuando alcanzan rango de universalidad estética, como, por ejemplo, la tendencia introvertida que se encuentra en el llamado arte apolíneo, o extrovertida en el dionisiaco.

Estas dos proyecciones de la sensibilidad artística - para mencionar una dicotomía clásica- las interpretamos nosotros como puntos clave de una polaridad dialéctica no excluyente, por cuya virtud los diversos estilos no son apolíneos o dionisiacos, sino ambas cosas a la vez, en diferentes grados de realización, coeficientes variables de un producto que en último término es la obra misma. Conservamos la dualidad introversión-extroversión, apolínea-dionisiaca, como categorías universales que por ellas mismas se vinculan en el proceso creador y en la obra misma. Hemos hecho un ensayo de interpretación histórica del arte a partir de esta dualidad, con ambos hemisferios, que tienen su demarcación ecuatorial en el concepto básico del arte, que establecemos como expresión intuitiva del sentimiento.

He aquí los planos de estimación histórica-estilística en la dialéctica estética:
a. Singularidad radical de una obra.
b. Periodo en la producción de un artista.
c. Estilo personal que lo caracteriza.
d. Escuela trascendente en que se ubica.
e. Época histórica a la que pertenece.
f. Género introvertido o extrovertido.
g. Concepto del arte como expresión.

De acuerdo a esta serie de planos graduales en la conceptuación estética, el método dialéctico estriba en transitar de uno a otro, prosiguiendo la secuencia indicada por la sucesión misma, que ha de ser respetada en su configuración original. No es posible efectuar el ascenso directo de lo singular a lo universal, que equivaldría a predicar de una obra, simplemente que es una obra de arte; la predicación resultaría inoperante por falta de elementos indicativos que la reconstruyan en lo concreto y en lo histórico, de acuerdo a su génesis individual. Ubicándola en un estilo determinado se aumentarán nuevos datos a la especificación; a medida que ésta se prolongue, los datos 
serán más abundantes y se incrementará la elocuencia explicativa de la disciplina.

Ésta es la verificación dialéctica que corresponde al método históricoestilístico y consiste en la captación de los caracteres que determinan la obra de acuerdo a su posición en la trayectoria evolutiva, como parte de un estilo histórico y manifestación de un espíritu cultural. Esta modalidad metódica es altamente fecunda para ese género de trabajos y constituye

- una relevante manifestación del método historiográfico de la filosofía.

\section{La dialéctica axiológica-calológica}

La dialéctica en la estética se establece también a partir de la axiología del arte, exhibiendo la dinámica del valor como belleza realizada en las obras; lo bello del arte corresponde al propósito originario de la expresividad que realiza cada estilo, cada época y desde luego las obras mismas. La misión del arte consiste en realizar una expresión, y cuando ésta se lleva a cabo, genera un valor. La dialéctica axiológica atiende a la correlación de los diversos aspectos del valor estético, que equivalen a las distintas formas de expresión en la belleza artística. Este sentido dialéctico se traduce en la corporación dinámica de las obras en los estilos, que no existiría sin la enriquecida diversidad de expresiones que motivan la realización de lo bello.

Sin esta modalidad dialéctica, el juicio valorativo de una obra se efectuaría en términos escuetos de buena o mala, bella o fea; no tendría en cuenta que una producción puede ser lo primero en algunos aspectos y lo segundo en otros; una misma obra puede tener partes buenas y malas, como sucede realmente en la gran mayoría de los casos.

La dialéctica axiológica incluye la posibilidad de que una obra sea desigual, que reúna atributos y valores opuestos, como los que denota la polaridad bueno-malo, bello-feo, en distintos grados de realización. Pero aun suponiendo el caso de una obra maestra que fuera excelente en todas sus facetas, la dialéctica consistiría en la unidad de los valores genéricos y específicos y, con ellos, en la dinámica estructural que existe sin excepción en cualquier obra.

Una composición tan famosa como, por ejemplo, la Novena Sinfonia de Beethoven, exhibe ambas posibilidades. La polaridad bueno-malo le conviene, porque no toda ella es magistral; tiene ciertas lagunas en su orquestación y altibajos en su desarrollo agógico; hay momentos de intensa dramaticidad que elevan al máximo la expresión artística, y por consiguiente, su belleza, junto a otros que la reducen notablemente, al grado que compositores tan responsables como Ricardo Wagner y Felix Weingartner, decidieron meterle mano a la partitura para enmendar la plana al genio de Bonn.

Pero en su aspecto general, a pesar de todo, es una obra maestra; en ella 
encontramos valores sublimes como pueden ser los vocales, junto a los instrumentales, los de armonía y los de polifonía, melodía, ritmo, etc. Contiene prominentes valores humanistas que se expresan en el texto de la Oda a la alegría de Schiller. Hay en cada elemento técnico un valor que se organiza en torno a la unidad estructural de la obra y produce en la relación formal de sus elementos el tercer género dialéctico que nos proponemos comentar: la dialéctica técnica de las estructuras.

\section{La dialéctica estructural-técnica}

El fundamento de la dialéctica axiológica está dado en los elementos que integran el vínculo orgánico de la obra, mediante su correcta estructuración para efectuar la expresión deseada, no sólo como una idea temática global, sino también y fundamentalmente como unidad técnica de los valores concretos. La dinámica tiene lugar mediantè el juego de contrastes y complementaciones que dan "movimiento" a la obra, promoviendo la unidad formal y estilística con el equilibrio que neutraliza la ruptura producida por el tránsito de un elemento a otro. Por ello, la tercera manifestación de la dialéctica estética es la estructural y corresponde a la modalidad técnica del arte.

Observemos la estructura que reciben las diferentes partes de una obra, consideradas de acuerdo a su dimensionalidad física y su ubicación funcional axiológica. En el caso de una obra musical, dichas partes son de orden temporario, ya sean los movimientos de una sinfonía, o partes menores como los periodos, las frases, los incisos e inclusive las notas musicales.

En la danza encontramos posiciones, evoluciones y composiciones individuales y de conjunto, que son integrantes de la coreografía; en una obra plástica contemplamos directamente las formas y cualquier fragmento que se elija permitirá circunscribir los respectivos valores de organización; también la literatura consta de elementos sectoriales, como los capítulos, parágrafos, oraciones y frases de un libro, que llegan incluso a las palabras y las letras; también los versos, estrofas y acentos en la poesía se organizan dinámicamente en la estructura formal. Otro tanto sucede con el teatro y la ópera, cuyos actos, deliberadamente seccionados, dan ocasión al descanso de público y artistas; las partes de una película cinematográfica son las tomas, escenas o secuencias. $Y$ así sucesivamente.

Cuando hablamos de partes, elementos o secciones en una obra, no queremos cifrar el análisis estético en una partición material de espacio o tiempo, sino precisamente en el análisis que se requiere establecer para la distinción de las funciones técnico-estructurales, sólo que espacio y tiempo intervienen necesariamente en cuanto constituyen categorías inherentes a la producción. El organismo técnico de las obras es sumamente complejo y se 
dilata en toda la extensión de sus dimensiones estructurales, que lo son porque convienen a toda la estructura y no sólo a algunas de sus partes. Sin embargo, dentro de la estructura coexisten elementos mayores y menores, pero están vinculados y sirven al común propósito de la idea concebida en el desarrollo de cada obra y de cada elemento o "parte" de la misma.

Como el desarrollo del arte requiere la participación de elementos y formas, para que la estética pueda explicarlos fielmente es necesario que los ubique en el sitio que ocupan por la constitución de la obra. Este enfoque integral sitúa dinámicamente a todos los elementos con la función axiológica que les corresponde, y con el valor que realizan; paralelamente a ella va aparejado el método, consistente en reconocer y fomentar dicho carácter. El caso contrario a esta apreciación estructural se observa generalmeñte en la actitud del diletante, que se limita a disfrutar pasivamente una obra, pero no llega a estudiarla analíticamente, como una fase preliminar a su reconstrucción y su comprensión dialéctica.

Nótese la singular importancia que tiene este método en los problemas estéticos; implica en cada uno la organiżación estructural tal como se manifiesta en la realidad. Debemos insistir en que este método es una polarización de la dialéctica en los problemas del arte, por cuyo motivo es correcto llamarlo dialéctica estética, o también estética dialéctica; ambas expresiones corresponden al método dialéctico aplicado a la investigación estética. Subrayemos finalmente que la diáléctica estética es posible en virtud de que existe la dialéctica artística, o sea la dialéctica creadora de las obras, fundada en la organicidad estructural del arte y realizáda a través de los elementos y formas de cada obra.

\section{La POSICIÓN METódica}

\section{Dogmaticidad y metodicidad}

Llegamos al final de nuestras reflexiones sobre el método en la investigación estética y, por consiguiente, a la fase que implanta una conciencia estética como obligado desenlace y fundamento de esta materia, exponiendo la importancia que tiene la posición metódica, entendida como postura dialéctica para el tratamiento de nuestra disciplina.

Posición metódica significa no solamente el ejercicio del método, sino la profunda disposición que auspicia la personalidad del estético, del historiador y crítico de arte, y del artista mismo, los cuales requieren, cada uno desde su peculiar atalaya, la ductilidad que exige una adecuada penetración en el variable repertorio de las formas artísticas. Entendemos por posición metódica la asimilación corporativa del método dialéctico, hasta el punto 
de hacerlo hábito en el profesional de la estética, de la crítica o de la creación artística; es la actitud espontánea para reconocer y justificar las categorías que hemos señalado, su dinamicidad y relatividad, así como su obligada reconstrucción en la unidad orgánica del proceso artístico.

Esta actitud es tanto más necesaria por cuanto, en relación al conocimiento de la estética -igual que en cualquier otro conocimiento-, un lamentable error que puede cometerse es la adopción de un criterio dogmático en torno a los problemas del arte; criterio amparado, en el mejor de los casos, en un solo aspecto de la verdad; rehúsa proseguir paralelamente a la evolución del arte y se estanca frente a él, pretendiendo valer en forma absoluta. Con esas características — parcialidad, estatismo y absolutismo- se define la posición dogmática, contraria a la metódica que, repetimos, se encuentra en la estética igual que en cualquier otra rama del conocimiento.

La posición dogmática es contraria a la metódica; lo opuesto a la dogmaticidad es la metodicidad: en vez de aceptar una verdad parcial -la versión más aceptable de un dogma, para no hablar de sus inverosímiles modalidades arcaicas - busca su totalización en los diversos problemas que comprende; no se estanca en una sola área; sino tiende a dilatarse por todo el horizonte de la disciplina. En ello consiste su dinamicidad; por último, a diferencia de la imposición absolutista de una tesis, se promueve su aceptación en los límites en que tiene validez; de ahí su insoslayable relatividad.

Así tenemos que a las características de parcialidad, estatismo y absolutismo, propias de la actitud dogmática, se oponen la totalidad, la dinamicidad y la relatividad, que caracterizan la actitupd metódica. El entronizamiento de estas categorias, y el consiguiente rechazo de aquéllas, es la mejor garantía para evitar el estancamiento inherente al dogmatismo y disfrutar las ventajas que reporta la posición dialéctica, por excelencia dinámica, pues convierte a la investigación en un proceso infinito, en una inagotable determinación del factum artístico, situándose en paralelo a la infinitud misma del arte, cuya creación se renueva constantemente y produce nuevas formas a las que deben corresponder nuevas determinaciones estéticas; acompaña la dialéctica del método fundamentante a la dialéctica de la producción histórica y la crítica de arte.

\section{La historia como método}

Esta connotación metódica debe hacerse extensiva a la historia del arte. Cierto es que la dimensión histórica corresponde a todas las expresiones de la cultura y, aún más, la dimensión temporaria se verifica en cualquier sector de la realidad. Las expresiones culturales muestran una evolución diacrónica que permite ubicarlas en el afluente integrativo que les corresponde. Si examinamos el Teorema de Pitágoras, por ejemplo, además del enunciado 
y la prueba correspondiente, se le envolverá en la circunscripción histórica que corresponde a la cultura de su época y a la evolución de la geometría. Pero sin esta ubicación, el enunciado y la prueba del teorema subsisten con su intrínseca validez apodíctica.

El caso del arte es distinto. La estética puede llevar a cabo la valoración de una obra per se y, sin embargo, la elocuencia de la excogitación técnica y axiológica - fases metodológicas que señalamos antes- quedará incompleta si no le acompaña la inmersión historiográfica que la sitúa en el seno de una producción conjunta, o un periodo de trabajo, en un autor, de éste en la escuela a que pertenece, y ella en el estilo y la época que le son propios.

La indispensable vinculación de la estética a la historia del arte constituye una permanente proyección de los criterios excogitativos en la trayectoria evolutiva de la creación y erige a la historiografía no tanto como una ciencia independiente, sino como un método de hacer estética. Eso vale igualmente para la estética que para la historia, es decir, la equivalencia de la estética como historia permite la recíproca, o sea la complementariedad de la historia como estética; no concebimos una verdadera estética que prescinda de la acotación histórica del arte, ni una auténtica historia que pudiese eliminar los criterios técnicos y valorativos que titulan a la conceptuación estética.

La simbiosis de diacronía y sincronía se verifica, según hemos dicho, en todo el campo de la cultura, pero quizá por razones de la mayor vinculación que tiene el arte con su época, en cuanto expresión directa de una forma de ser y vivir, la demarcación histórica es más precisa, llega directamente al fondo de su esencialidad vivencial y compele a incorporar tanto a la estética como a la historia del arte en una misma unidad determinativa. Hacer estética sobre los hitos evolutivos del arte: esto es lo que significa la historiografía como método.

\section{La estética como método}

El criterio básico que fundamentan las reflexiones anteriores nos lleva a una amplia identificación que estipula en términos generales a la filosofia como método, como un proceso inextinguible de infinita determinación. El sentido metódico de esa postura - característica de la escuela criticista- se funda en el hecho de proseguir continuamente sobre un camino abierto, en el tránsito de un punto a otro, como indica la significación prístina del método. Efectivamente, si método es camino, o sea determinación abierta e infinita, nada mejor que adoptar la postura metódica -metodicidad dialéctica- como norma indefectible del filosofar, pues en última instancia lo que no se metodiza en conocimiento integral, dinámico y progresivo, se convierte en dogma, que a ello equivale el conocimiento parcial, estático y absolutista. 
Afirmando que la filosofía es método, reconocemos el deber de continuar siempre en el camino de la determinación abierta y progresiva, la única que asegura el avance del pensamiento y, en su seno, el progreso de la estética, de la filosofía y del arte.

\section{La estética como método}

La perspectiva que hemos seguido, tendiente a mostrar la importancia medular del método en la investigación estética —como en toda forma de pensamiento nos lleva a reconocer que la estética misma es método, conocimiento estructural e integrativo, como corresponde a todo genuino pensamiento filosófico que pretenda llegar al fondo del problema, y develar la compleja trama de coeficientes y resultantes que configura cualquier expresión cultural.

La consecuencia de esta postura repercutirá en el conocimiento del arte; consiste en no limitarse a ninguno de los aspectos que presenta su problemática sino en incluirlos a todos, manteniendo el problema de cada uno y manejándolos con la autonomía metodológica imprescindible para el buen éxito de la investigación, autonomía más necesaria a medida que se amplía la demarcación aporética de su tratamiento. Mientras más compleja, mayor será la disciplina dé su rigurosa metodización y el consiguiente acoplamiento de sus soluciones.

La razón para hablar de la estética como método y no simplemente del método en la estética, consiste en que el hilo conductor de esta disciplina - determinación y comprensión de la belleza artística - no se agota en la estética misma, extendiéndose a todas las formas de conocimiento que puedan producir las ciencias que se ocupan, directa o indirectamente, de estudiar al arte como obra y como hecho histórico, como fenómeno psicológico y social, como organización de materiales y, en último término, como revelación de una manera específica de comprender el mundo y sentir la existencia.

En esta última pretensión radica el viejo anhelo de los filósofos: la interpretación estética del mundo y de la vida, una Kunst-Welt-und-Lebensan. schauung, la cosmovisión estética que encontramos desde la más remota antigüedad cultural. En efecto, desde las primeras culturas prehistóricas, mucho antes de una concepción científica o filosófica del mundo, se encuentra una concepción estética, en paralelo a la imagen religiosa del universo. Las primeras manifestaciones culturales del hombre que revelan una profundidad total de la expresión y alcanzan el rango de obras maestras, son de carácter estético. No hay, en el hombre de las cavernas, una obra suya que nos maraville más que su pintura rupestre, la cual permanece todavía como una expresión insuperable del espíritu; buena parte de los artistas contemporáneos 
la imitan en un gesto de audacia modernista, o la emplean como una sublime distorsión y estilización de las formas visuales.

Aun los primitivos simbolismos de la religión, en su forma de magia o mitología, están envueltos en formas plásticas, en formas estéticas, como si la belleza fuese lo que más importa al hombre antiguo, como si los sentidos se abrieran primero al cauce de las emociones para expresar directamente su intuición del mundo por el conducto artístico. Entonces, ¿cómo limitar el conocimiento del arte a la descripción escueta de sus formas y sus colores, por más elocuentes que pudieran ser? ¡No! Hay que penetrar en todas las dimensiones de la expresión estética y en todas las facetas de la vida artística, que son al mismo tiempo las posibilidades de interpretar a la vida con un tono de belleza, como si lo bello y lo sublime fueran los atributos supremos de la existencia.

Esta preponderancia que tiene la estética para producir una cosmovisión basada en la corriente intuitiva y en los datos sensoriales que proporciona la vivencia artística, ha orillado en repetidas ocasiones a improvisar los rasgos de la cosmovisión sobre datos provenientes de la subjetividad, lo cual equivale a una trasposición al campo de la intersubjetividad, y en su caso extremo, a una hipóstasis ontológica del arte. Tal circunstancia abre la compuerta a una especie de dictadura estética, no sólo sobre la estética misma sino también sobre el arte, cuyo inconveniente fundamental puede consistir en su raíz subjetivista, en su alteridad con respecto al arte, en su indeclinable modalidad de motivación individual.

"Se trata de una disposición subjetiva que no debería reñir con la objetividad del arte y la estética, sino al contrario, necesitará afirmarla en cuanto refrendada profesión y observación imparcial de los hechos. Para ello se debe trascender el hábito que tiende a colocar la emoción individual en una cumbre de altivez desde la cual se querrían dictar leyes infalibles a la creación artística. Al mismo tiempo, sería la estética el receptáculo de las vehemencias de quien, no pudiendo desahogarlas por conducto del arte, lo hace inventándole motivaciones que no son las suyas y atribuyéndole categorías que no le pertenecen. En vez de ello es necesario reconocer las genuinas categorías autónomas que hacen posible, por una parte, la creación artística $y$, por la otra, el desenvolvimiento de una cosmovisión arraigada en la experiencia estética, pero sólo en ella.

\section{Originalidad del arte}

En todo esto háy que evitar uno de los vicios que acusa con mayor frecuencia la "filosofía del arte", el que proviene del deseo de originalidad que se encuentra en algunos tratadistas y que, en su extremo, pretende ejercer un mandato por cuyo efecto se impondrían reglas a la misión y la obra del 
artista. Esgrímense argumentos como, por ejemplo, que la obra de arte es captación del "ser en cuanto tal", o que el artista es "el hombre que se identifica con su interioridad", o que el arte produce "la unión del hombre con la naturaleza", o que la forma estética es "el acto de aprehender la entelequia", y muchísimas otras frases que por regla general son bastante oscuras, con el agravante que restaturan o inventan una terminología metafísica obsoleta en vez de los conceptos que deberían amparar a las teorías estéticas, las verdaderamente filosóficas.

En cuanto al primer punto, recordaremos que el único lenguaje capaz de explicar al arte es el que se refiere en concreto a las obras, el que emplean la historia, la teoría y la técnica del arte, vertientes por donde corren las afluencias de la estética, de la única verosímil y justificable: la estética del arte.

Así, la mejor forma de hacer estética de la plástica - por ejemplo- será emplear los conceptos que se utilizan para construir las bases del arte espacial, tales como proporción, perspectiva, composición, armonía, colorido, contraste y muchos otros que no sólo permiten realizar la teoría, sino también la estética del arte, aplicándola a la valoración de las obras. En cuanto a la música, no podrán sustituirse parámetros como sonoridad, melodía, ritmo, polifonia, y tantos otros que exponen la esencia de las obras musicales, sin necesidad de recurrir a incomprensibles términos exhumados de la metafísica. Y si alguien desea llevar a cabo una estética de la poesía, ¿cómo hacerlo prescindiendo del metro, la rima, la estrofa, la cadencia, etc., que son titulares en la teoría estética de las letras? En ningún caso es posible remplazar la terminología especifica del arte por alguna suerte de disquisiciones ontológicas que provocan artificialmente la oscuridad de comprensión y exposición, en detrimento de la veracidad y profundidad de los conceptos.

Por lo que respecta al segundo punto, o sea la originalidad estética, tal como están las cosas, la mejor forma de ser original consiste en renunciar a serlo; en vez de ello hay que comprender, con toda la modestia del caso, que en materia de teorías sobre el arte, la iniciativa corresponde a los artistas, porque son ellos quienes tienen a mano la facultad de crear e imponer conceptos en su trabajo, ejerciendo el oficio que permite traducir las ideas en formas, las formas en materiales y los materiales en obras.

Ante este dominio de la concepción de las formas y ejecución de los materiales, el estética debe comprobar lo que hacen los artistas, y precisamente en los términos como lo llevan a cabo. Sobre este factum, el filósofo proyectará su originalidad discursiva en el ámbito de la recreación conceptual del arte, convirtiéndose potencialmente él mismo en un artista; el profesional del arte será quien decida sobre las formas de su obra, y reconocerá que la sola aptitud artística no le capacita para resolver discursivamente sobre su valor y todo lo que puede saberse de ella; ingresará.entonces al campo de la filosofía. 
Ambos casos presentan edificantes ejemplos; en ellos comprobamos que la estética y el arte están indisolublemente ligados, péro la actividad profesional del artista creador y su inherente originalidad son irreductibles; no se debe procurar el forzoso e imposible remplazo de una por la otra.

\section{El estético y el artista}

La culminación de nuestras reflexiones, dirigidas al método en la investigación estética, nos lleva finalmente a aplicar este concepto en su más amplio significado, como saber del arte. Concluimos que este saber puede arbitrarse por diversos conductos que convergen al interés común de la obra artística, terreno al mismo tiempo probatorio de su esencia y su valor. Además de los caminos cuya convergencia está cifrada en términos de dialéctica metodológica, hay dos personas o tipos de personas que están particularmente avocadas al conocimiento del arte: el filósofo-estético y el artista-técnico. Cada uno se encuentra en un punto de vista peculiar que, sin embargo, debe también coordinarse en términos dialécticos y desembocar en el delta común a todos los afluentes en que se ramifica la caudalosa corriente del saber en el arte.

El estético debe guardar una estrecha relación frente a la obra de arte, que conserva en todo momento la prioridad temporal y la primacía jerárquica frente a las observaciones que quieran explicarlo. La creación artística es siempre lo primero; el artista creador ejerce autoridad suficiente para dictar sus normas de realización. Esto significa que solamente el arte es capaz de señalar sus caminos, establecer sus reglas y construir sus conceptos; cualquier intento que se haga para imponerlos desde fuera tendrá que resultar frustráneo; en primero y último términos, el artista conserva la libertad de hacer el arte conforme a sus deseos, sus recursos y sus materiales, sin acatar opiniones externas, ni siquiera las ideas "filosóficas" que desde un sitio ajeno a la realidad han querido muchas veces imponer los cánones de su producción. En vez de ello, es indispensable reconocer la autonomía del arte, su posibilidad y necesidad de autorregularse y, sobre la obra creada, llevar a cabo la critica que se considere pertinente.

Esta inmediatez, y aún más, esta inmersión del artista en su obra, le brinda una postura privilegiada para ejercer la estética y la crítica de arte; cuando menos en principio, nadie como él estaría capacitado para entender y reconocer las técnicas empleadas, para adentrarse en sus internas motivaciones, para develar el secreto de su propia creación. Hablando en rigor, todos los estéticos deberían ser artistas, y recíprocamente, todos los artistas deberían ser estéticos; no es concebible realizar la obra maestra a espaldas de una severa crítica. Pero desgraciadamente ni todos los artistas son estéticos ni todos los estéticos son artistas. Quizá lo contrario; sólo una minoría 
cumple con el doble requisito de crear el arte y ejercer el juicio crítico del arte.

Pero ésta es una situación de hecho que en nada desmerece el principio de derecho; si los artistas no son estéticos se debe principalmente a que su interés se dirige casi exclusivamente a lo que ellos hacen, y por efecto del gran amor que le tienen a su obra propia, acostumbran desconocer la obra ajena. En cuanto a los estéticos, provienen casi siempre del seno filosófico y se incuban en un ambiente de abstracción, ajeno a la realidad artística; están más al lado de las especulaciones que caracterizan al filosofar metafísico que en la inmanencia distintiva de la creación artística.

El ideal que debe ser propuesto en forma terminante radica en la incorporación de la actividad artística a la estética, y viceversa: en hacer que todos los artistas sean filósofos del arte. Pero este ideal colinda con la utopía; no creemos que pueda efectuarse en un futuro previsible. En tan difícil capacitar al artista para ejercer la estética, como al filósofo para producir el arte; la creación artística lleva implícita una estética y para hacerla explícita se requiere la disposición objetiva, la postura metódica a que nos hemos referido, y la vocación para traducirla en obra escrita, facultades ambas que no son comunes a la personalidad del artista, subjetivo y temperamental por excelencia.

El artista no ha sido siempre el más capacitado para percibir el sentido dialéctico del arte. Se ha demostrado en numerosas ocasiones que la historia consagra con un valor definitivo ciertas obras que su propio autor había considerado inferiores; este fenómeno, extraño y difícil de explicar, autoriza a sostener que el artista, por falta de esa disposición objetiva, no ha sido siempre el más capaz para valorar su propia obra, y menos aún la ajena.

Parece que existe una cierta disposición - una especie de vicio profesional- a permanecer incomprensivo frente a la obra de los demás, debido en parte a la individualidad del artista y a sus diferencias de carácter con otros artistas; así se producen los recelos y susceptibilidades que motivan la confronta de dos actitudes frente al arte, cuando se es protagonista de una de ellas. Y de ahí proviene también el hecho, bastante reconocido, de que los menos indicados para juzgar conceptualmente al arte han sido los artistas mismos; aquí aparece la necesidad del estético-filósofo para explicar al arte por medio de una reflexión profesional, dialéctica, metodológica y sistemática.

\section{La "frialdad" del estético}

Una de las equivocaciones que se cometen con más frecuencia en relación a la necesaria imparcialidad del discurso estético, radica en creer que la filosofía debe fomentar una emotividad análoga a la que se observa en el 
arte, de manera que el estético debería, ante todo, cultivar un hermoso estilo literario y conmoverse profundamente con los temas que maneja, pues se trata nada menos que de la belleza, y ella debe inspirar asimismo la más profunda emoción en el lector.

Desde luego, hay que aplaudir el buen estilo en cualquier género de escritos, y el teórico del arte debe estar capacitado para ejercerlo; pero no debemos creer que la principal virtud de una teoría estética consiste en ser expuesta precisamente "con estética", es decir, con grandes virtudes de finura y elegancia, como si se tratara de una obra literaria y no de una reflexión filosófica, que es tanto como decir una reflexión científica.

No olvidemos que la estética es una teoría del arte y no el arte mismo; su obligación consiste en explicarlo, no necesariamente en hacerlo vivir. De esto último se encarga el arte en cuanto tal, mientras que el filósofo debe observar con objetividad, inclusive con frialdad, la estructura técnica de las obras y sus motivaciones emocionales para discernir el valor que puedan contener en la expresión. La principal virtud del estético, ya actúe como filósofo, como crítico, o como historiador del arte, consiste en la disposición objetiva para reconocer el valor de las obras, y en ello la emotividad puede no ser la mejor virtud, quizá al contrario, convertiríase en un impedimento para reconocer en toda su amplitud el mundo de los valores estéticos, ya que gran parte de ellos pueden desentonar de la sensibilidad personal, en cuyo caso terminaría negándolos, como de hecho sucede con frecuencia.

Pero no sólo en este aspecto la emotividad corre el riesgo de ser contraproducente para el estético, sino también por la exposición que sugiere veladamente un doble camino heterodoxo; primero, sentirse obligado a un discurso retórico, en menoscabo de la precisión conceptual; y segundo, el engaño que puede producir al lector poco advertido una doctrina errónea, cuando se envuelve en un hermoso ropaje literario.

En estas condiciones, el estético estará más obligado con la honradez de sus convicciones, la objetividad de sus conceptos y la claridad de sus exposiciones, únicamente cuando ha cumplido estos requisitos puede alentar la emotividad, revistiendo al tratadismo conceptual con el vistoso ropaje de la imaginería. Si a cambio de la hermosura lingüística sacrifica la claridad de los conceptos, llegará a cometer errores que pueden repercutir en la alteración de las doctrinas y la deformación interpretativa de las obras. Hagámonos cargo de este requerimiento para entender a quienes cumplen con la honradez de una sobria convicción, antes de procurar a todo trance el lucimiento virtuosístico de una exposición hermosa.

Miguel Bueno

INSTITUTO DE INVESTIGACIONES FILOSÓFICAS

Universidad Nacional Autónoma de México 